\title{
Drogas, direitos humanos e bioética: dupla vulnerabilidade do usuário de drogas em situação de rua*
}

Drogas, derechos humanos y bioética:

la doble vulnerabilidad del consumidor de drogas habitante de calle

Drugs, human rights, and bioethics:
double vulnerability of street drug users

Fecha de recepción: 16 de diciembre de 2016

Fecha de evaluación: 14 de marzo de 2017

Fecha de aceptación: 2 de mayo de 2107

Disponible en línea: 22 de mayo de 2017

Andréa Leite Ribeiro Valério**

Wanderson Flor do Nascimento***

Cómo citar:

Ribeiro Valério, A. L. y Flor do Nacimento, W.

(2017). Drogas, direitos humanos e bioética: dupla vulnerabilidade do usuário de drogas em situação de rua. Revista Latinoamericana de Bioética, 17(2), 63-75. DOI: http://dx.doi.org/10.18359/rlbi.2677

* $\quad$ Artigo de reflexão.

** Graduada em Serviço Social, mestre em Políticas Sociais e Cidadania pela Universidade Católica do Salvador (UCSAL) e doutoranda em Bioética, Programa de Pós-Graduação em Bioética da Universidade de Brasília. Atualmente é membro do comitê científico do portal Aberta Universidade Federal de Santa Catarina/ Secretaria Nacional de Políticas sobre Drogas (SENAD) Brasilia, Brasil. E-mail: aleitevalerio@gmail.com. ORCID: http:// orcid.org/0000-0003-4917-4469

*** Graduado em Filosofia, mestre em Filosofia e Doutor em Bioética. Membro da Rede Nacional de Religiões Afro-Brasileiras e Saúde.Co-lider do Grupo de Pesquisa e Estudos sobre Gênero e Relações Raciais Audre Lorde (UFRPE/UnB/CNPq). Professor do Programa de Pós-Graduação em Bioética da Universidade de Brasília, Brasil. E- mail: wandersonflor@unb.br. ORCID: http://orcid.org/0000-0002-3250-3476 
A primeira política nacional sobre drogas do Brasil foi criada em 2002, através de um decreto presidencial. Desde então, a mesma passou por reavaliação no ano de 2003 e por atualização e realinhamentos, deixando de ser uma política antidrogas e passando a ser uma política sobre drogas. Em 2006 houve a criação de um sistema nacional de políticas sobre drogas. Desde então o Brasil vivencia avanços e retrocessos no que tange a atenção aos vulneráveis sociais usuários de drogas. Dessa forma, o presente texto busca problematizar, através da reflexão de legislações e de textos nacionais e internacionais a dupla vulnerabilidade: uso de drogas e situação de rua, numa perspectiva bioética e dos direitos humanos. Concluímos que o campo da bioética poderá contribuir para este debate, especialmente no que concerne a aqueles que vivem a dupla vulnerabilidade: o uso de drogas e a rua como seu lugar de vida e sobrevivência. Esse texto discutirá, também, os direitos humanos dos usuários que estão em situação de rua, desde uma perspectiva bioética.

Palavras-chave: drogas, população de rua, bioética, direitos humanos.

La primera política nacional sobre drogas en Brasil fue creada en 2002 por medio de un decreto presidencial. Desde entonces, esta política fue objeto de reevaluación en 2003 y por actualización y realineamientos, dejando de ser una política anti-drogas y para convertirse en una política sobre las drogas. En 2006 se produjo la creación de un sistema nacional de políticas sobre drogas. Desde entonces, Brasil experimenta avances y retrocesos en lo que atañe a la atención de los vulnerables sociales usuarios de drogas. De esta manera, este artículo busca cuestionar, a través de la reflexión de legislaciones y de textos nacionales e internacionales la doble vulnerabilidad: el consumo de drogas y habitantes de calle, desde una perspectiva bioética y de los derechos humanos. Llegamos a la conclusión de que el campo de la bioética podrá contribuir a este debate, especialmente con respecto a los que viven la doble vulnerabilidad: el uso de drogas y la calle como su lugar de vida y sobrevivencia. Este texto analiza también los derechos humanos de los usuarios habitantes de calle, desde una perspectiva bioética.

Palabras clave: drogas, población de calles, bioética, derechos humanos.

\section{Abstract}

Brazil's first national drugs policy was created in 2002 through a presidential decree. Since then, it has been reassessed in 2003 and updated and realigned, ceasing to be an anti-drug policy and becoming a policy on drugs. In 2006 there was the creation of a national drug policy system. Since then Brazil has experienced advances and setbacks regarding care to vulnerable social users of drugs. In this way, the present text tries to problematize, through the reflection of national and international legislation and texts, the double vulnerability: Drug use and the street situation from a bioethical and human rights perspective We conclude that the Bioethics can contribute to this debate, especially on those who live the double vulnerability of drug use and homelessness. This paper also analyses the human rights of those living on the streets, through a bioethical approach.

Keywords: drugs, street population, bioethics, human rights. 


\section{Introdução}

O presente texto se propõe a apresentar o quanto a ética aplicada pode contribuir para iluminar as questões éticas implícitas nos debates teóricos e prático frente às pessoas que fazem uso problemático de drogas e estão em situação de rua, tendo como base a abordagem bioética sobre a problemática da vulnerabilidade em sua dimensão social. Dessa forma, não serão abordadas as bases conceituais e nem fundamentos da Bioética ${ }^{1}$.

As linhas que seguem buscarão fazer a aproximação de estudantes, pesquisadores e profissionais que atuam na área da drogadição, para o debate bioético envolvido tanto nas práticas biopsicossocial, quanto nas pesquisas sobre a temática.

Como veículo para as discussões, utilizaremos a Declaração Universal sobre Bioética e Direitos Humanos (Unesco, 2005), que dispõe de 28 artigos, dentre os quais discutiremos os princípios neles presentes referentes a não estigmatização, não discriminação, solidariedade, equidade, justiça, responsabilidade social e saúde e dignidade humana.

$\mathrm{Na}$ atualidade, é possível constatar a crescente desigualdade social relacionada à faixa etária, renda, sexo, cor e região do país em que vive e o quanto isso vem afetando socioeconomicamente e psicologicamente as pessoas. Dados do Instituto Brasileiro de Geografia e estatística apontam que 37,4\% dos domicílios do Brasil não possuem ao mesmo tempo, rede de esgotamento sanitário da água e nem coleta de lixo. Aponta ainda que a metade dos jovens com idades

1 Para o aprofundamento sobre a Bioética, indicamos a leitura dos textos que estão disponíveis no sitio eletrônico da Sociedade Brasileira de Bioética, através do endereço eletrônico http://www. sbbioetica.org.br/textos-e-publicacoes/. de 15 a 17 anos, estão fora da sua faixa etária escolar. No que tange ao universo do trabalho, o Instituto aponta que na região nordeste do Brasil, 90,5\% das mulheres trabalham sem carteira de trabalho e previdência social. (Instituto Brasileiro de Geografia e Estatística [IBGE], 2015) Já os dados do Instituto de Pesquisa Econômica Aplicada, em sua publicação Retrato das Desigualdades de Gênero e Raça, apontam o quanto esses dois aspectos são estruturantes das desigualdades brasileiras, as quais contribuem significativamente para o agravamento da exclusão, da pobreza. (Instituto de Pesquisa Econômica Aplicada [IPEA], 2011). Questões como o mercado de trabalho, habitação e saneamento, acesso a bens duráveis e a serviços de saúde, de educação, limitam a progressão de oportunidades e ampliam as desigualdades sociais. Tais repercussões podem ser constatadas no aumento do número de pessoas que estão vivendo em condições indignas e com precariedade de recursos de todas as ordens.

No que toca o uso de drogas, pode-se constatar que a rua acolhe tanto aqueles que por motivos diversos perderam as suas residências fixas e que, por essa condição, acabam por fazer uso de alguma substância, por vezes, para melhor lidar com o sofrimento da sua nova condição de vida, quanto é motivador para que pessoas deixem as suas casas e encontrem na rua um local para fazer o consumo da droga, longe das repercussões familiares e comunitárias. Em ambas circunstâncias, existe um cidadão que por motivos diversos iniciou o consumo da droga.

Vale ressaltar que o uso de drogas não necessariamente se revela em um problema para a vida social, econômica e para a saúde da pessoa que a usa. Conforme afirma Antônio Nery Filho, os humanos usam drogas porque são humanos (Filho e Valério, 
2010) e nesse sentido, existirão pessoas que experimentarão o consumo de alguma substância psicoativa legal ou ilegal e tal vivência só se reverterá em problemas para a sua vida. Nesse texto, trataremos especialmente daqueles que fazem uso problemático de drogas, ou seja, um uso que repercute negativamente em vários aspectos da sua vida, fazendo um recorte naqueles que as pesquisas apontam como os mais vulneráveis para o uso abusivo de drogas. Conforme aponta Garcia, "para compreender por que alguns humanos, mais humanos do que outros, tem problemas com o uso de drogas, é preciso revelar as condições individuais e sociais dessa incorporação" (2016).

O estudo (levantamento nacional sobre o uso do crack) realizado pela Fundação Oswaldo Cruz e que ficou denominado como Pesquisa do crack, apontou que, dentre os que fazem uso de drogas e estão em condição de rua, perfazem homens (78,68\%), negros ou pardos (77,73\%), com baixa escolaridade $(57,60 \%$ tem o ensino fundamental), sem profissão definida e com idade entre 18 e 24 anos. A pesquisa publicada em 2014, contou com 7.381 usuários nas cenas de uso e mostrou que nas capitais 47,3\% dos usuários de crack encontravam-se em situação de rua e o aspecto que esses consideram importante está o favorecimento do seu acesso aos serviços de saúde e de assistência social e a alimentação e a possibilidade de ter espaço para fazer a sua higiene pessoal, bem como oferta de apoio para conseguir emprego, escola/curso e atividade de esporte e lazer (Bastos e Bertoni, 2014).

Ainda nessa perspectiva, a pesquisa coordenada por Jesse Souza, por nome A Gênese Social do Crack (Souza, 2016), revela as vulnerabilidades e as desigualdades vivenciadas pelos excluídos sociais, usuários de drogas e em situação de rua, apontando o quanto a organização social e racial do Brasil acentua a pobreza e dificulta o acesso dos que necessitam do Estado para acessar serviços e ter a sua cidadania garantida (Souza, 2016).

Aliado a esses dados, a Presidência da República através da Secretaria Nacional da Juventude, publicou em maio de 2015 o Mapa da Violência: Mortes por Arma de Fogo, que vem sendo apresentado desde 1998 . O resultado da pesquisa mostra que de 1980 até 2012, a população brasileira que teve crescimento de cerca de 61\%, teve um aumento de mortes por arma de fogo de $387 \%$. Contudo, os dados ficam mais alarmantes se considerarmos que mais de $460 \%$ das mortes dessa natureza, alavancadas pelos homicídios, tem, na sua maioria, destino certo: jovens negros. "Racismo, violência e impunidade se associam na degradação do ambiente social brasileiro" (Waiselfisz, 2015). Em 2012 as mortes por arma de fogo atingiram 10.632 brancos e 28.946 negros, representando 11,8 óbitos para cada 100 mil brancos e 28,5 para cada 100 mil negros. Os dados revelam que as pessoas negras vítimas dessa natureza de morte teve uma taxa de $142 \%$, em 2012 , ou seja, duas vezes e meia a mais que os brancos, sendo trágico evidenciar a seletividade dos negros enquanto vitimas desse tipo de morte. Em 2003, a vitimização negra por homicídio no país era de $72,5 \%$, e em 2012 foi dobrada passando para $142 \%$.

Além desses dados, em junho de 2015, o Ministério da Justiça apresentou os dados do encarceramento no Brasil, anunciando que $35 \%$ do número de presos no Brasil se dão pelo tráfico de drogas, sendo esse o delito com maior número de presos no país. O número revela que pela primeira vez, o tráfico está em primeiro lugar no número de encarcera- 
mento, estando acima do roubo, que tradicionalmente é o delito que mais encarcera. Aqui, vale apontar que o perfil dos 515.284 presos do Brasil, traz em sua maioria jovens e negros, sendo possível problematizar que a vigilância esta mais focada para esse público. Temos no Brasil 1,5 mais negros presos que brancos presos e $54,8 \%$ dos presos é constituído de jovens (Secretaria-Geral da Presidência da República, 2015).

E o que há de comum entre esses dados? Todos apresentam os jovens, na faixa etária de 18 a 24, do sexo masculino, negros (ou não brancos) e residentes e/ou oriundos de bairros periféricos enquanto a população mais vulnerável e para os quais as políticas públicas devem incidir, reconhecendo que não se trata de um problema de natureza individual, mas sim de um grupo social significativo.

A suposta epidemia do crack revela a questão estrutural de desigualdade do Brasil, em que os direitos são menos garantidos para os jovens negros e a seletividade nas prisões, exclusão e homicídio se dá para esse grupo social, sendo a prova incontestável da necessidade de tratar conferir de que tipo de direitos esses humanos dispõem efetivamente. Se for analisada a história de vida desses jovens que formam as estatísticas do governo, é possível constatar que se trata de pessoas que já eram socialmente excluídas e o uso de drogas, encarceramento e a vivência em situação de rua, confirmam suas trajetórias de exclusão, acirrando sua condição e fazendo com que sofram ainda mais as consequências das injustiças sociais.

O julgamento antecipado que os usuários de drogas sofrem revela o fracasso de uma política repressiva que discrimina e vulnerabiliza os grupos que já estão à margem de quase todos os direitos sociais, gerando, por vezes, formas de consumo cada vez mais perigosas. Nesse sentido, aqueles que tinham problemas para conseguir uma vaga no mercado de trabalho, de permanência nos bancos escolares, de relacionamento com os seus pares, dentre outros, passam a ter apenas um problema: os efeitos nocivos (especialmente os sociais) do consumo da droga. É tomar a droga enquanto consequência e não causa!

Diante desse cenário, apresentaremos abaixo como é possível utilizar os princípios determinados pela Declaração Universal sobre Bioética e Direitos Humanos para debater os aspectos bioéticos implícitos na questão da drogadição especificamente, no Brasil. Como não é comum à discussão sobre o uso problemático de drogas por meio dos referenciais bioéticos, faremos uma breve apresentação desta jovem área de conhecimento e discussão, enfatizando uma de suas perspectivas nascida no Brasil: a Bioética de Intervenção.

\section{Bioética de intervenção}

O grande avanço das ciências, impulsionando o desenvolvimento das tecnologias, foi uma das características marcantes do século XX. Esse século foi também cenário de graves crimes cometidos em nome do progresso dessas mesmas tecnologias e ciências. Ao utilizar seres humanos como parte de seus experimentos, a produção científica estruturou roteiros muito violentos que despertaram apreensão não apenas na comunidade científica, como nas sociedades, de modo geral. Durante a Segunda Guerra Mundial, pudemos assistir a realização de uma grande quantidade de experimentos que demonstraram a crueldade 
desta produção contemporânea de conhecimento (Beauchamp e Childress, 1979).

Além desses casos, podemos verificar ainda alguns outros exemplos de como a pesquisa clínica para a produção de terapias ou drogas eram violentos. Descrições aterrorizantes sobre a utilização, em 1938, de sulfanilamida, entre 1959-1960 de talidomida, a investigação sobre sífilis em parte da população negra de Tuskegee, Estados Unidos (entre 1932 e 1972), a pesquisa acerca do câncer na população idosa em um hospital judaico no Brooklyn, Nova Iorque - EUA, em 1963 ou, também, sobre a hepatite em crianças com retardo mental, diversas vezes em troca de postos de trabalho na escola Willowbrook, Nova Iorque, em 1967. Estes são casos, entre tantos outros, em que vemos a produção de conhecimento colocada acima do respeito pela vida e dignidade de participantes das investigações (Beecher, 1966; Lott, 2005).

A reação social apresentou-se através da demanda pelo estabelecimento de reflexões e de delimitações para o modo como as investigações e procedimentos são realizados em relação à vida humana, a partir de uma abordagem ética, que evidenciem os conflitos morais que envolvam a tecnologia, a saúde e a vida.

É nesse cenário que os primeiros esforços de construção da bioética como reflexão e prática preocupadas com os diversos conflitos entre desenvolvimento dos conhecimentos científicos ou tecnológicos e proteção de seres humanos, como também as dificuldades de decisão acerca de intervenções que impactem a vida e a saúde. A bioética surgiria, sistematicamente, apenas na década de 1970, partindo das discussões sobre o prosseguimento de investigações ou ações noci- vas aos seres humanos, mesmo após as discussões sobre as consequências das investigações científicas no contexto da Segunda Guerra (Garrafa, 2005).

A bioética, então, surge para refletir eticamente sobre questões que surgem com a prática da medicina, das ciências biológicas e das tecnologias associadas à vida na sua aplicação no que tanja à vida dos seres humanos, buscando alternativas para as práticas de pesquisa e produção de conhecimento minimizando a violação de sujeitos envolvidos no processo.

Com o surgimento e primeiros desenvolvimentos da bioética nos contextos estadunidenses e mais voltados para as discussões biomédicas, hegemonizou-se uma perspectiva em torno da ética biomédica, baseada em uma universalização de princípios de orientação liberal e de aplicação limitada em países em desenvolvimento ou subdesenvolvidos. Em reação a este cenário, a América Latina colocou-se em um contexto crítico dessa abordagem biomedicalizada, buscando interagir com os contextos socioeconômicos que se relacionam com a saúde e a qualidade de vida, trabalhando com um contexto ampliado de saúde que não observe apenas as dimensões orgânicas, mas também as sociais, políticas e econômicas (Garrafa, 2006a).

Entre as propostas bioéticas latino-americanas, a Bioética de Intervenção se estrutura como uma proposta de que enfatiza a necessidade de politizar as abordagens dos conflitos morais, e estabelece como orientação um posicionar-se ao lado dos sujeitos mais vulneráveis, face às diversas esferas do poder na esfera social. Contrapondo-se a uma abordagem bioética restrita à aplicação de apenas alguns princípios (Autonomia, Beneficência, Não-Maleficência e Justiça) oriundos do prin- 
cipialismo bioético de origem estadunidense, que se apresentam como norteadores universais de avaliação de conflitos morais na esfera biomédica, a Bioética de Intervenção se apresenta como uma perspectiva combativa aos problemas sociais que impactam a vida e a saúde, ultrapassando, assim, o contexto clínico para o mundo da vida, em suas diversas dimensões, atenta às necessidades sociais normalmente prevalentes em regiões mais pobres do planeta, tendo como marco fundamental a reflexão sobre as múltiplas formas de vulnerabilidade social como vetores de conflitos bioéticos, incorporando a perspectiva dos Direitos Humanos (Fulgêncio e Nascimento, 2012).

Base importante para a atuação da Bioética de Intervenção é exatamente a Declaração Universal sobre Bioética e Direitos Humanos, que, em sua constituição contou com a participação efetiva de países da América Latina, determinando uma agenda sanitária e a introdução de valores sociais que fortaleçam os vínculos solidários e críticos entre os seres humanos como princípios da Declaração (Garrafa, 2006b).

Em sua abordagem mais biomédica, a bioética pouca atenção deu à questão do uso nocivo de drogas, sobretudo em função de um olhar que privilegie a dimensão da autonomia das pessoas. Ao atentar-se aos processos sociais que vulnerabilizam os sujeitos, a Bioética de Intervenção procurará observar de que maneira o uso abusivo e, sobretudo, a atenção que se dá ao sujeito adicto em dependência prejudicial estabelecem conflitos morais que impactam a (qualidade de) vida de usuários, as sociedades nas quais estão inseridos e os sistemas de saúde, evitando abordagens meramente moralizadoras que culpabilizam o usuário de drogas e preconizando uma intervenção que desconsidere direitos humanos da população usuária de drogas. A Bioética de intervenção se inseriria na reflexão dos conflitos morais envolvendo a atenção aos usuários em nível prejudicial de drogas evitando a estigmatização e a consequente vulnerabilidade que surge em função da atenção, ou ausência desta, à população usuária.

\section{Usuário de drogas em situação de rua}

Nesse ponto, discutiremos as práticas de saúde junto a usuários de drogas em situação de rua, que mais estigmatizam e os vulnerabili$\mathrm{za}$, fazendo com que muitos rechacem a oferta de cuidados em saúde, por desacreditarem na possibilidade de ter a sua necessidade atendida.

Devido ao fato de muitas substâncias psicoativas serem proibidas, quem faz uso dessas é visto como alguém que quebrou as regras e, por esse motivo, merece menos assistência à saúde e ao social. Desse modo, sua condição de cidadão perde lugar, sendo essa pessoa reconhecida apenas como um usuário de drogas. Os usuários de drogas são marcados pelo estigma e a noção de "animalização" do usuário, especialmente dos que esta em situação de rua, naturaliza praticas que lhes retiram a autonomia e o seu reconhecimento enquanto cidadão. (Souza, 2016). O pesquisador Souza aponta que "A esmagadora maioria dos usuários autodestrutivos do crack [e outras drogas] é construída socialmente pelo seu abandono secular e pela experiência de humilhação cotidiana que ela implica" (Souza, 2016).

Deixando de ser reconhecido como cidadão e em nome do direito à saúde, por vezes violam-se os direitos humanos dos usuários 
de drogas que estão em situação de rua em que o tratamento compulsório ou internação compulsória são impostos, sendo o seu recolhimento involuntário pouco questionado e os efeitos negativos dessas intervenções minimizados, supostamente, "em nome da vida". Dessa forma, a liberdade de escolha, a cidadania e o exercício da autonomia não poderá ser exercida por esse grupo de vulneráveis. A retirada do seu direito se dá pelo "pânico social" em torno do usuário de drogas em situação de rua, não reconhecendo que se trata de um povo que no seu percurso individual traz consigo o acumulo de desvantagens e diversas exclusões sociais. Muitos desses vulneráveis, considerado por Mayora (2016), como os "desclassificados sociais" e que moram na rua, são filhos de moradores de rua e trazem na sua história de vida o abandono, privação, violência, institucionalizações, tem amigos e/ou familiares que foram mortos ou presos (eles mesmos por vezes possuírem histórico de prisão). Trata-se de desfiliados (Castel, 1994) que não possuem capital social, não têm a quem recorrer em situações de emergência na qual se coloca a exigência de um retiro temporário (Mayora, 2016).

São pessoas que, "recebem tratamento discriminatório por parte de instituições como a polícia e os programas de assistência social" (Dutra e Henriques, 2016) Nesse ponto, o que é trazido para o debate é o direito ao acesso a serviços de saúde. O Sistema Único de Saúde preconiza que o acesso aos serviços é para todos, porém, o próprio sistema cria barreiras para aqueles que possuem uma cidadania aparente ou cidadania de papel como coloca Gilberto Dimenstein (Dimenstein, 2011), a exemplo da exigência de apresentação do documento de identidade e comprovante de residência para acessar o sistema de saúde.
Na contramão de práticas tradicionais de atenção ao usuário de drogas e em situação de rua, vale discorrer sobre a estratégia denominada Consultório de Rua. A estratégia do Consultório de Rua nasceu na cidade de Salvador enquanto atividade do Centro de Estudos e Terapia do Abuso de Drogas (CETAD), Serviço Especializado da Faculdade de Medicina da Bahia (FMB/UFBA) que tem o objetivo de cuidar dos usuários de drogas legais e ilegais, particularmente crianças e adolescentes em situação de rua. Trata-se de um dispositivo móvel, que com uma equipe interdisciplinar formada por assistente social, psicólogo, enfermeira, redutor de danos, dentre outros atores, realiza atendimento às pessoas que estão em situação de rua e em uso de drogas nas cenas de uso da cidade de Salvador. Nessa atividade a rua é considerada enquanto o espaço daqueles que lá estão e o atendimento/aproximação ocorre mediante o desejo do usuário. Os profissionais que atuam no serviço trabalham na perspectiva de reconhecimento da cidadania desses, bem como da sua singularidade, limites e possibilidade (Filho, Valerio e Monteiro, 2011).

Outra estratégia que lida diretamente com as necessidades dos usuários de drogas em situação de rua na perspectiva da garantia de direitos e acesso a serviços de saúde e assistência social, bem como dignidade humana é o Ponto de Cidadania ${ }^{2}$. Trata-se de um contêiner instalado na cidade de Salvador, em local de grande aglomeração de usuários de drogas em situação de rua e que favorece a atenção integral aos usuários, possibilitando, além do acolhimento, o tratamento e a ressociali-

2 Matéria sobre o projeto disponível em http:// www.secom.ba.gov.br/2015/07/126798/Pontosde-Cidadania-ja-realizaram-167-mil-atendimentos-em-Salvador.html; https://www.youtube. com/watch?v=njggo_vCM1M 
zação. Busca ainda promover o cuidado com a saúde, o autocuidado e a cidadania (Flach, 2013). Ambas as estratégias não impõem condições para o acesso e se coloca como uma possibilidade para aqueles que desejam um espaço para tomar banho e cuidar da sua higiene, ter contato com os profissionais e tratar de questões psicossociais que lhes aflige, ter acesso a rede de saúde, assistência social, além de ser uma ponte entre os visíveis sociais e os invisíveis sociais.

Estratégias como o Consultório de Rua e o Ponto de Cidadania, buscam diminuir o hiato entre a garantia de direitos humanos para todos e a realidade excludente que criminaliza o usuário de droga, de forma mais violenta com aqueles que estão em situação de rua. Em ambos os casos, a sua maioria é de jovens e negros. Nesse sentido, a política pública deve intervir para que os direitos humanos de todos os cidadãos seja assegurada de forma que os mais vulneráveis não vivam de forma degradante.

Tais estratégias incidem nos direitos humanos dos usuários de drogas e que estão em situação de rua, "apostando" na constituição e fortalecimento de vínculos e laços sociais tocando numa dimensão ética fundamental para a atenção - psicossocial desse grupo social.

\section{Declaração universal sobre bioética e direitos humanos aplicados ao campo da drogadição}

A perspectiva da estigmatização se insere na prática de efetivação de algumas políticas enquanto um complicador seja para imprimir o estigma ao usuário de drogas, seja por ser impactada por este mesmo estigma. A ima- gem que construímos dos usuários impacta, de modo decisivo, os modelos de atenção que daremos aos sujeitos em um serviço ou dificultar seu acesso a um determinado serviço ou política. Por isso, é fundamental que busquemos analisar a relação que estabelecemos com as imagens estigmatizadas de usuários de drogas, sob a pena de cercear a estes o direito humano à saúde e sua atenção.

A Declaração Universal sobre Bioética e Direitos Humanos parte da necessidade de que as sociedades, governos e indivíduos devem ser conscientes da necessidade de "perceber a injustiça, evitar o perigo, de assumir responsabilidades, de buscar cooperação e demonstrar o sentido moral que dá expressão aos princípios éticos" (Unesco, 2005, p. 2). Por isso, incorpora a perspectiva dos direitos humanos para preconizar que todas as pessoas devem se beneficiar dos padrões éticos nos serviços de saúde, sem exceção.

O artigo 11 da Declaração afirma explicitamente que "nenhum grupo deve ser discriminado ou estigmatizado por qualquer razão, o que constituiria violação da dignidade humana, aos direitos humanos e liberdades fundamentais" (Unesco, 2005, p. 7). Não discriminar ou estigmatizar os usuários de drogas implica em garantir a eles o acesso que se prestaria a qualquer outra pessoa aos serviços de saúde, assistência social, educação, justiça, de forma a garantir-lhes o bem estar e qualidade de vida, sem fazer julgamentos morais que condenem os usuários a serem responsáveis por sua condição e negando-lhes atenção às suas necessidades básicas e os direitos de cidadão. Muito embora nossas sociedades tenham um discurso ambíguo com relação ao uso de drogas ilícitas, não se pode, por tal princípio, discriminar e imprimir uma imagem negativa aos usuários destas drogas 
para, com isso, impedir seu acesso aos vários sistemas de saúde, proteção, educação e a um atendimento digno, sob pena de operar com uma distinção entre classes de seres humanos que sejam merecedoras de atenção à saúde e outras que não o sejam.

Em seu artigo 13, a Declaração determina a solidariedade como um princípio a ser estimulado (Unesco, 2005, p. 8). E, nesse cenário, podemos ter a relação solidária com os usuários de drogas como parâmetro para evitar que a estigmatização retire deles direitos que deveriam ser garantidos. $O$ contexto social no qual se insere a maioria dos usuários de drogas é parte do processo problemático do uso nocivo das drogas e ter esse elemento em vista significa que em vez de responsabilizar os usuários por sua situação, devemos coletivamente nos empenhar para reduzir o impacto dos efeitos nocivos do uso das drogas nesses usuários e na sociedade como um todo. A solidariedade aparece como uma ferramenta de relação "comprometida, interventiva - que visa à transformação social na busca de políticas públicas democráticas e equitativas - e produz mudanças em nível individual e coletivo" (Selli e Garrafa, 2006, p. 249).

Por propor intervenções equitativas, essa noção de solidariedade se vincula diretamente com o princípio trazido pelo artigo $10^{\circ}$ da Declaração, que afirma que "A igualdade fundamental entre todos os seres humanos em termos de dignidade e de direitos deve ser respeitada de modo que todos sejam tratados de forma justa e equitativa" (Unesco, 2005 , p. 7). A equidade nos convoca a estabelecer um tratamento diferenciado às pessoas em função de sua situação vulnerabilizada, de modo que o resultado desse tratamento seja a condição de igualdade, como modelo de justiça social. Deste modo, as políticas volta- das ao enfrentamento da drogadição devem estar atentas às especificidades dos usuários e à determinação social destas, de modo a ter uma orientação precisa de que elementos vulnerabilizadores devem ser combatidos para que tais políticas tenham um efeito benéfico para os usuários, garantindo a estes uma melhor qualidade de vida.

Um dos mais importantes artigos da Declaração é o $14^{\circ}$, que determina a relação Responsabilidade Social e Saúde, que determina que os governos têm como objetivo central a promoção da saúde e do desenvolvimento social a serem partilhados por todos os setores da sociedade (Unesco, 2005 , p. 8). A responsabilidade social aparece como função fundamental para o direcionamento das ações das políticas públicas na direção de promover o bem-estar social; e na determinação da Declaração, todos os setores sociais devem, igualmente, partilhar o que for alcançado pelas políticas. No que diz respeito ao enfrentamento dos efeitos nocivos da drogadição, as políticas são responsabilidade dos governos e devem empenhar-se não apenas por ter um retorno social, mas por ser um dever para com os grupos que são prejudicados pelo uso maléfico das drogas. Há um compromisso, portanto, com a população em geral e com a população drogadicta, na promoção da saúde e do bem estar social.

O artigo $3^{\circ}$ da Declaração determina que a "dignidade humana, os direitos humanos e as liberdades fundamentais devem ser respeitados em sua totalidade" (Unesco, 2005, p. 6). Esta determinação do respeito à dignidade não se restringe apenas àquelas pessoas que não estão em conflito com a lei, que não usam substâncias ilícitas ou que são julgadas pelo olhar social como "boas cidadãs". O respeito à dignidade é princípio fundamental dos 
direitos humanos e deve ser considerado em qualquer sociedade que se pretenda democrática e que tenha como objetivo um mínimo de bem-estar social. A garantia de que a dignidade de pessoas que façam uso nocivo de drogas deve, por tanto, ser também almejada, promovida, planejada através de políticas públicas.

\section{Conclusão}

As drogas sempre existiram em diferentes sociedades e em diferentes contextos. Contudo, o que tem se revelado no Brasil é uma violação dos direitos humanos daqueles que fazem uso de drogas ilegais resultando em uma guerra com público alvo definido: negros e jovens. Dessa forma, políticas focalizadas que tenham incidência na desigualdade social, no racismo e na vulnerabilidade do jovem são urgentes.

Faz-se necessários investimentos nas ações de prevenção nas escolas e nas comunidades com estímulo ao protagonismo juvenil, fortalecimento de vínculos familiares e sociais que possam incidir na diminuição do consumo já iniciado e/ou retardamento da idade de experimentação. Trata-se de buscar a melhoria de vínculos institucionais, dos fortalecimentos de projetos de vida e da ampliação da participação de sujeitos e coletivos nas ações de prevenção para favorecer políticas locais, sejam elas sociais ou comunitárias.

A utilização de novas tecnologias como forma de alcance aos mais jovens, com vistas à mudança no modelo de comportamento de risco também é um caminho desejável para a garantia dos direitos humanos e prevenção do uso de drogas.

Ainda de forma preventiva, atuar nas políticas econômicas a exemplo de economia solidária, equidade, justiça distributiva são formas de tratar do abismo social que uma parcela da população esta exposta. Políticas de inclusão social, acesso a moradia descente, digna e sustentável, a exemplo das moradias sociais, a socialização, o trabalho e o tratamento com baixa exigência, a exemplo do que oferta o programa de braços abertos em São Paulo e o Ponto de Cidadania na Bahia são medidas que apontam uma nova forma de lidar e assegurar a cidadania de pessoas que estão em uso de drogas e situação de rua, sem violação dos seus direitos e nem submissão a tratamentos degradantes ou que os retirem da sua comunidade. Não podemos deixar de mencionar a necessidade de ampliação e/ou melhora do financiamento da rede de Centro de Atenção Psicossocial Álcool e outras drogas (CAPS_ad) para qualificar o cuidado em saúde no campo da drogadição.

A qualificação da sociedade civil para atuar efetivamente no controle social, bem como o fortalecimento dos conselhos, a exemplo do Conselho Nacional sobre drogas e os Conselhos Estaduais e Municipais, sociedade civil organizada e os fóruns é fundamental para a garantia da não violação dos direitos dos usuários.

O debate sobre os direitos humanos daqueles que estão em uso de drogas e em especial aqueles que vivem a dupla vulnerabilidade por estarem em situação de rua requer uma discussão da sociedade civil, bem como dos órgãos responsáveis sobre a proibição às drogas que por vezes cria crimes sem vítimas, quando muitas vezes os seus direitos enquanto humanos lhes foram negados, retirados ou negligenciados.

É importante apontar também a redução de danos enquanto uma possibilidade de tratamento de baixa exigência e que ofer- 
ta alternativa de inclusão e exercício da autonomia desses sujeitos. Trata-se de incluir os usuários no seu processo de tratamento de forma participativa, dentro de uma lógica do possível, com objetivos intermediários, escalonados, com foco na pessoa e não na substância que utiliza, no seu estilo e qualidade de vida.

Por fim, as leituras que a Bioética de Intervenção pode fazer para a avaliação dos conflitos morais que estão em jogo no atendimento em saúde às pessoas que fazem uso nocivo de drogas, nos indicam que as possibilidades de enfrentamento das condições sociais que facilitam ou induzem sujeitos ao uso das drogas ilícitas de modo prejudicial é fundamental para que a própria sociedade crie condições para o desenvolvimento das potencialidades das pessoas em direção às suas mais diversas dimensões, abrindo espaços para que a sociedade reflita de modo adequado sobre o uso das drogas, sobre seu impacto social, sobre os contextos nos quais essa prática se dá e, sobretudo, para um encaminhamento para as situações nas quais se faça necessária uma intervenção para a promoção da saúde e do bem estar social e que não exclua a população usuária de drogas.

\section{Referências}

Bastos, F. I. e Bertoni, N. (Orgs.) (2014). Pesquisa nacional sobre o uso de crack: quem são os usuários de crack e/ou similares do Brasil? Quantos são nas capitais brasileiras? Rio de Janeiro: Instituto de Comunicação e Informação Científica e Tecnológica, Fiocruz.

Beauchamp, T. L. e Childress, J. F. (1979). Principles of biomedical ethics. Nova York: Oxford University Press.
Beech, H. K. (1966). Ethics and clinical research. En J. M. Humber e R. F. Almeder (Eds.), Biomedical ethics and the law (pp. 193-205). Springer US. DOI: https://doi. org/10.1007/978-1-4615-6561-1_14

Brasil, Ministério da Justiça. (2014). Levantamento nacional de Informações penitenciárias. INFOPEN-Junho-2014. Brasília: Departamento Penintenciário Nacional [Depen].

Brasil, Presidência da República. Secretaria Geral. (2015). Mapa do encarceramento: os jovens do Brasil. Brasília: autor.

Brasil, Secretaria-Geral da Presidência da República (2015). Mapa do Encarceramento: os jovens do Brasil. Brasília.

Castel, R. (1994) Da indigência à exclusão, a desfiliação: precariedade do trabalho e vulnerabilidade relacional. Em A. Lancetti (Org.), Saudeloucura 4: grupos e coletivos (pp. 21-48). São Paulo: Hucitec.

Dimenstein, G. (2011). O cidadão de papel: A infância, a adolescência e os direitos humanos no Brasil. São Paul: Ática.

Dutra, R. e Henriques, V. (2016). O poder discricionário dos agentes institucionais que lidam com usuários de crack: invisibilidade de classe e estigma de gênero. En J. Souza (Org.), Crack e exclusão social. Brasília: Ministério da Justiça e Cidadania, Secretaria Nacional de Política sobre Drogas.

Filho, A. N. e Valério, A. L. R. (Orgs.) (2010). Módulo para capacitação dos profissionais do projeto consultório de rua. Brasília, Salvador: Secretaria Nacional de Políticas sobre Drogas [SENAD], Centro de Estudos e Terapia do Abuso de Drogas [CETAD]. 
Filho, A. N., Valério, A. L. R. y Monteiro, L. F. (Orgs.) (2011). Guia do projeto consultório de rua. Brasília, Salvador: Secretaria Nacional de Políticas sobre Drogas [SENAD], Centro de Estudos e Terapia do Abuso de Drogas [CETAD].

Flach, P. M. V. (2013). Do ponto de cidadania ao ponto de encontro. Em J. Mara Selete Bessa, L. A. Bonfim, P. E. Dias e L. L. de Lima (Orgs.), Olhares plurais sobre o fenômeno do crack. Fortaleza: Universidade Estadual do Ceará [UECE].

Fulgêncio, C. A. e Nascimento, W. F. (2012). Bioética de intervenção e justiça social: olhares desde o sul. Revista Brasileira de Bioética, 8(1-4), 47-56.

Garcia, L. S. L. (2016). Apresentação. Em J. Souza (Org.), Crack e exclusão social (pp. 11-15). Brasília: Ministério da Justiça e Cidadania, Secretaria Nacional de Política sobre Drogas.

Garrafa, V. (2005). Introdução à Bioética. Revista do Hospital Universitário - UFMA, São Luís, 6(2), 9-13.

Garrafa, V. (2006a). Declaração universal de Bioética e direitos humanos da Unesco uma vitória dos países do terceiro mundo. Boletim SBB, Londrina - PR, Brasil março, 6.

Garrafa, V. (2006b) O novo conceito de Bioética. Em V. Garrafa, M. Kottow eA. Saada (Orgs.). Bases conceituais da bioética. Enfoque latino-americano (pp. 9-15). São Paulo: Brasil Gaia.

Instituto Brasileiro de Geografia e Estatística [IBGE]. (2015). Síntese de indicadores sociais: uma análise das condições de vida da população brasileira Coordenação de População e Indicadores Sociais. Rio de Ja- neiro: Instituto Brasileiro de Geografia e Estatística, [IBGE].

Pinheiro, L. Fontoura, N. D. O., Querino, A. C., Bonetti, A. e Rosa, W. (2011). Retrato das desigualdades de gênero e raça. Brasília: Instituto de Pesquisa Econômica Aplicada Brasília [IPEA].

Lott, J. P. (2005). Vulnerable/special participant populations. Developing World Bioethics, 5(1), 30-54. DOI: https://doi.org/10.1111/j.1471-8847.2005.00101.x

Mayora, M. (2016). O crack e a Rua. En J. Souza (Org.), Crack e exclusão social. Brasília: Ministério da Justiça e Cidadania, Secretaria Nacional de Política sobre Drogas.

Selli, L. e Garrafa, V. (2006). Solidariedade crítica e voluntariado orgânico: outra possibilidade de intervenção societária. História, Ciências, Saúde, 13(2), 239-51. DOI: https://doi.org/10.1590/ S0104-59702006000200003

Souza, J. (2009). A ralé brasileira: quem ée como vive. Belo Horizonte: Editora Universidade Federal de Minas Gerais [UFMG]. Souza, J. (Org.) (2016). Crack e exclusão social. Brasília: Ministério da Justiça e Cidadania, Secretaria Nacional de Política sobre Drogas.

Unesco. (2005). Declaração universal sobre bioética e direitos humanos. Brasília: Cátedra Unesco de Bioética, Sociedade Brasileira de Bioética [SBB].

Waiselfisz, J. J. (2015). Mapa da violência 2015: mortes matadas por arma de fogo. Flacso Brasil. Acessado em: 19 de novembro de 2016, dehttp://www.mapadaviolencia. org.br/pdf2015/mapaViolencia2015.pdf 